\title{
Por que (não) fugir da matemática? A (re)significação dos conteúdos no tempo comunidade da educação do campo ${ }^{1}$
}

\author{
Why (not) run away from mathematics? The (re)signification of content in the
} community time of field education

Débora Schmitt Kavalek Ariele Maria Santos dos Reis

Resumo: Na busca por uma ressignificação dos conceitos na disciplina de Introdução a Matemática no curso de Licenciatura em Educação do Campo, buscamos, na etnomatemática, uma alternativa para trabalhar de forma que não excluísse a população do campo que, com suas distintas dificuldades, haviam retomado os estudos depois de muitos anos. Apresentamos, no artigo a seguir, um relato e análise de uma atividade didática realizada numa turma do segundo período do curso de Licenciatura em Educação do Campo, tendo como objetivo principal a reconstrução da visão de matemática pelos discentes, numa conexão entre os conteúdos e o trabalho das mulheres e homens camponeses. Os estudantes utilizaram a linguagem matemática para expressar como os agricultores fazem matemática, escolhendo um produto/serviço, pesquisando dados e calculando os custos de produção e lucros. 0 desenvolvimento da atividade didática proporcionou informações sobre as possibilidades, as potencialidades e limites de usos da etnomatemática no âmbito da educação do campo. $\mathrm{O}$ artigo explicita como essa atividade pedagógica foi proposta e como os alunos responderam a ela.

Palavras-chave: Educação do Campo. Etnomatemática. Ensino de matemática.

Abstract: In the search for a reframing of the concepts in the discipline of introducing mathematics in the field education degree course, we seek, in ethnomathematics, an alternative to work in a way that does not exclude the population of the field who, with their different difficulties, had resumed their studies. studies after many years. We present, in the following article, a report and analysis of a didactic activity carried out by a class from the second period of the Degree in Rural Education, with the main objective of reconstructing the view of mathematics by the students, in a connection between the contents and the work of peasant women and men. Students used mathematical language to express how farmers do mathematics, choosing a product / service, researching data and calculating production costs and profits. The development of the didactic activity provided information about the possibilities, potentialities and limits of uses of ethnomathematics in the field of rural education. The article explains how this pedagogical activity was proposed and how students responded to it

Keywords: Field Education. Ethnomathematics. Pedagogy of alternation. Math teaching.

\footnotetext{
${ }_{1}^{1}$ Agradecemos à Pró reitoria de extensão (PROEX), Universidade Federal do Espírito Santo (UFES) pela bolsa concedida.
} 


\section{Introdução}

"Eu não aprendo matemática".

"Faz muito tempo que parei de estudar".

"Odeio matemática".

"Sou das humanas, não preciso aprender matemática".

Essas frases, afirmadas pelos estudantes matriculados na disciplina de Introdução à Matemática, marcaram nossa recepção numa turma que assumimos em nosso primeiro ano de docência no ensino superior, com cerca de 70 alunos do segundo período do curso de Licenciatura em Educação do Campo. Após resistência inicial da turma, partimos para a busca de uma maneira de trabalhar os conhecimentos matemáticos de forma que não excluísse a população do campo que, com suas distintas dificuldades, haviam retomado os estudos depois de muitos anos. Diante disso, foi necessário conhecer, entender e apontar as possibilidades de inserção da etnomatemática em atividades de ensino e de aprendizagem de conceitos matemáticos na educação do campo, tendo em vista uma ressignificação do sentido da matemática para essa turma. Sendo assim, através da etnomatemática, buscamos as conexões entre a educação do campo e os conceitos matemáticos.

Especificamente, o presente artigo apresenta as repercussões de um trabalho realizado no Tempo Comunidade ${ }^{2}$, por uma turma do segundo período do curso de Licenciatura em Educação do Campo da Universidade Federal do Espírito Santo, no âmbito da disciplina de Introdução à Matemática, tendo como objetivo principal a (re)construção da visão de matemática dos discentes. A pesquisa partiu do entendimento de que existem muitas atividades em cada cultura que possuem componentes matemáticos que podem ser identificados, estudados e relacionados à matemática corrente. Sendo assim, a questão posta aos futuros professores das escolas do campo foi: Os agricultores fazem matemática? Como?

2 No Curso de Licenciatura em Educação do Campo, as etapas presenciais são equivalentes aos semestres de cursos regulares, e são realizados em regime de alternância entre Tempo Universidade (uma semana por mês) e Tempo Comunidade (o restante do mês). 
Tais repercussões são examinadas através das inter-relações que foram sendo estabelecidas pelos diferentes atores sociais envolvidos no processo: produtores rurais, cooperativados, feirantes, docente e alunos. Os procedimentos e método utilizados na parte empírica da investigação envolveram observação direta e participante, realização de entrevistas e coleta de depoimentos por parte das(os) estudantes, para montar uma planilha com custos de produção e lucros referentes a um serviço ou produto gerado na comunidade de origem da(o) aluna(o). Os referenciais teóricos adotados no trabalho levam em consideração a etnomatemática e seus princípios de interrelação com conteúdos de matemática. Com a atividade, esperava-se que os estudantes percebessem a matemática acadêmica escolar como uma das matemáticas possíveis, fruto de um processo civilizatório. Os registros escritos e orais das atividades desenvolvidas, bem como as intervenções realizadas, discussões, proposições realizadas durante o trabalho, constituem o corpus de nosso estudo que será apresentado ao longo da nossa escrita.

Pretende-se refletir, portanto, através do desenvolvimento desta pesquisa, sobre as possibilidades, as potencialidades bem como os limites de usos da etnomatemática no âmbito da educação do campo. Qual o papel da etnomatemática na educação do campo? Desse modo, qual o lugar e o papel da matemática nessa licenciatura, com um vínculo tão arraigado ao desenvolvimento humano, social e político dessa população?

\section{A etnomatemática e sua importância na educação do campo}

A partir década de 60 do século XX, ocorreu uma mudança nos currículos de matemática na maior parte dos países, inclusive no Brasil, com o movimento chamado matemática moderna ou nova matemática. Pesquisadores desse movimento (SOARES, 2009; PINTO, 2005) expõem que o conceito matemático mais relevante dessa reforma foi a noção de conjunto. O currículo da matemática moderna passou então a utilizar símbolos, pretendendo que a teoria dos conjuntos fosse ensinada a todos os estudantes, através de linguagens simbólicas e definições abstratas, em todos os níveis de escolaridade. 
No Brasil, a matemática moderna iniciou junto aos primeiros congressos brasileiros do ensino de matemática ${ }^{3}$. O movimento, embora tivesse tido grande repercussão até mesmo internacional, não foi rapidamente absorvido como proposta para a sala de aula de matemática no Brasil. A questão do "que ensinar" e "como ensinar" a matemática no país, sempre foi atrelada à postura tradicional, e à educação matemática dada nas faculdades de filosofia, um ensino atrasado em relação aos outros países. Somente a partir de 1970, de acordo com Soares (2009) é que são apresentadas outras tendências mais recentes da matemática moderna, desenvolvidas em outros países, porém as maiores críticas em relação ao ensino da matemática no Brasil se davam pela falta de motivação dos jovens com abstrações acima de seu nível de maturidade. Diversos pesquisadores consideram que a matemática moderna trouxe inúmeros danos ao ensino da matemática no Brasil (GOMIDE, 1980; SANGIORGI, 1975; KLINE, 1976).

$\mathrm{Na}$ verdade, atestam os educadores e pesquisadores matemáticos que o fracasso do Movimento da Matemática Moderna no Brasil foi devido, principalmente, a um projeto gerado em países desenvolvidos e que teria sido posteriormente transferido para países do Terceiro Mundo sem ter sido desenvolvido de forma adequada, não respeitando as condições socioeconômicas e culturais de cada país (BANDEIRA, 2016, p. $52)$.

Essa tradição brasileira de adotar práticas e currículos de outros países como modelos para regerem o nosso sistema educacional com pleno apoio dos dirigentes brasileiros, principalmente de currículos americanos, trouxe diversos prejuízos para o ensino de matemática. Uma matemática neutra e isenta de aspectos que pudessem favorecer uma análise crítica do cotidiano dos alunos, apoiada amplamente pelo regime militar.

Nesse cenário, questões como: as críticas à ênfase em exercícios que exigiam práticas exaustivas por parte dos alunos; a crítica às teorias de conjunto e às estruturas matemáticas; as primeiras discussões sobre resolução de problemas; a ligação da matemática com o entorno sociocultural trouxe novos rumos às discussões curriculares em matemática.

3 O I Congresso Brasileiro do Ensino de Matemática, realizado por iniciativa da Faculdade de Filosofia da Universidade da Bahia, em setembro de 1955. 
Foi na década de 80 do século $\mathrm{XX}$, através das reformas que ocorreram em vários países tentando implantar uma nova concepção de matemática, que muitos questionamentos foram estabelecidos e provocaram reflexões acerca do papel de fatores culturais, sociais, étnicos, idiomas, costumes e modos de vida envolvidos no ensino-aprendizagem desta disciplina

Sendo a educação um ato político, e o ensino de matemática não foge à regra, esta pode levar à subordinação, exclusão, passividade, como também, em sentido oposto, despertar no indivíduo curiosidade, exercício de crítica e questionamento da realidade. Porém percebe-se na história da matemática, de acordo com D'Ambrosio (2001), que a mesma está associada a um processo de dominação e poder desse processo.

D’Ambrosio (2001) concebe a matemática como uma estratégia desenvolvida pela espécie humana para explicar, entender, manejar e conviver com a realidade, dentro de um contexto. A matemática vista numa conjuntura mais ampla, natural, social, humana, que vai além dos cálculos. Dentro dessa concepção de Matemática, D’Ambrosio ressalta a etnomatemática, que, com suas raízes gregas (techné [tica] significando maneiras; matema significando fazer e saber, as explicações, os entendimentos, de seu próprio etno, que significa o meio ambiente natural e sociocultural) procura estabelecer estratégias cognitivas específicas de uma cultura para lidar com a realidade e categorias adequadas para construir conhecimento dessa cultura.

Desde o fim do século XIX os etnógrafos já utilizavam o termo etnociência (Sturtevant, 1964) e conceitos inter-relacionados como etnolinguística, etnobotânica, etnozoologia, etnoastronomia, etc. Bandeira (2016) aponta que a proposta da etnomatemática surge em meados da década de 1970, e abarca as ideias de educação de John Dewey (1859-1952), como a importância da aprendizagem a partir de interesses e motivações do aluno. Apoia-se também nas concepções de educação de Paulo Freire (1921-1997), principalmente no que se refere a ouvir e entender o outro para o desenvolvimento da aprendizagem, e incorpora características próprias, como o aspecto antropológico e histórico do conhecimento matemático. Apesar das ideias sobre a Etnomatemática terem iniciado durante as décadas de 60 e 70, foi somente 
nos anos 80 que encontrou condições históricas e políticas favoráveis para emergir no cenário oficial dos centros acadêmicos, segundo Marchon e Fantinato (2015).

Bandeira (2016) reuniu a conceituação de diversos autores que concordam que a Etnomatemática é a união de todas as formas de produção e transmissão de conhecimento ligado aos processos de contagem, medição, ordenação, inferência e modos de raciocinar de grupos sociais culturalmente identificados (GERDES, 1991; FERREIRA, 1997; KNIJNIK, 2006, apud BANDEIRA, 2016). Portanto, na visão desses autores, a etnomatemática procura entender, dentro do contexto sociocultural do indivíduo, do seu modo de vida, seus processos de pensamento e seus modos de explicar e de entender sua realidade, seu trabalho e o mundo, através da matemática. Sendo assim, esse campo prioriza o modo de fazer matemática dos grupos socioculturais, tidos como excluídos do conhecimento formal, já que a matemática não se configura como neutra e universal. Posto isso, nada mais considerável, do que envolver a etnomatemática, nesse contexto de educação fora dos padrões hegemônicos e tradicionais da matemática convencional, que é a educação do campo.

\section{3. $O$ curso de licenciatura em educação do campo}

As Licenciaturas em Educação do Campo, tão necessárias para uma educação do campo e para o campo, vem ganhando espaço no cenário educacional federal nos últimos anos, emergindo das lutas dos camponeses e dos movimentos sociais. Essas têm como objetivo formar professores com atenção às especificidades do campo e, junto aos sujeitos do campo, construir uma educação que legitime sua cultura, seu modo de ver o mundo, suas necessidades, racionalidades e crenças.

Os licenciados em educação do campo são habilitados a atuar nas escolas, zelando para que estas cumpram com a função de reforçar as culturas, os modos de vida, os saberes, as identidades locais, local de organização e discussão relacionados aos problemas sociais. Segundo Caldart (2005), o povo 
tem direito a ser educado no local onde vive, uma educação pensada e vinculada à sua cultura e necessidades humanas e sociais.

O curso de Licenciatura em Educação do Campo a que se refere esta pesquisa, é organizado pelo Departamento de Educação e Ciências Humanas (DECH), sendo ofertado pela Universidade Federal do Espírito Santo (UFES), e está vinculado ao Centro Universitário Norte do Espírito Santo (Ceunes). O curso oferece aos estudantes a opção de escolha em duas grandes áreas do conhecimento: Ciências da Natureza $(\mathrm{CN})$ ou Ciências Humanas e Sociais (CHS). A organização curricular supõe etapas presenciais (equivalentes a semestres de cursos regulares) em regime de alternância, que intercala um período na universidade e um período na comunidade, ou na escola do campo. O curso de Licenciatura em Educação do Campo, portanto, em sua organização, pretende evitar que o ingresso de jovens e adultos na educação superior reforce a alternativa de deixar de viver no campo. Dessa maneira, o curso prioriza a articulação entre a educação e a realidade das populações do campo.

\section{A disciplina de introdução à matemática}

Introdução à Matemática é uma das disciplinas presentes na matriz curricular do Curso de Licenciatura em Educação do Campo - Ceunes, segundo o PPC- Projeto Pedagógico do Curso (UFES, PPC, 2012), possuindo uma carga horária de 60 horas, e ofertada no $2^{\circ}$ período do curso. A disciplina apresenta como ementa: a discussão de alguns tópicos fundamentais de matemática elementar, indispensáveis para a formação da cidadania; abordar os conteúdos em seus aspectos conceituais, didáticos, históricos, sociais e culturais; fundamentos de álgebra e geometria essenciais para as ciências. A partir de 2019, a disciplina foi reformulada e passou a denominar-se "Matemática aplicada à Educação do Campo"(UFES, PPC, 2019).

Os objetivos da disciplina são: compreender elementos da matemática essenciais ao contexto do campo; desenvolver a capacidade de pensar e raciocinar, numa perspectiva contextualizada.

Os conteúdos desenvolvidos na disciplina são: conjuntos fundamentais; tipos de conjuntos; igualdade de conjuntos; operações com conjuntos; relações; 
o conjunto dos números naturais; números e numerais; sistemas de numeração; operações com números naturais; números racionais; fração e operações; numeral decimal e operações; geometria e unidades de medidas. Todos os conteúdos são apresentados e contextualizados a situações da vida campesina.

Dentro da pedagogia da alternância, deve propôr-se, no Tempo Comunidade (TC), atividades que relacionem os conteúdos vistos nas aulas da disciplina de Introdução à Matemática, à realidade do campo, do local de origem, aplicando seus conhecimentos na escola do campo ou na comunidade rural. Nesse sentido, ao ponderar o desenvolvimento da disciplina, pensou-se na proposta de um trabalho, no tempo comunidade, que interligasse os conteúdos ministrados no tempo universidade, à produção de uma planilha de entrada e saída de caixa, referente a uma atividade econômica, serviço ou produto produzido pela comunidade.

\section{O percurso metodológico}

\subsection{A turma}

O trabalho que será relatado foi realizado com estudantes do $2^{\circ}$ período do curso de Licenciatura em Educação do Campo, num total de 75 alunos, cuja idade varia entre 19 e 65 anos. Nessa fase do curso, os estudantes encontravam-se todos juntos, tanto os que optaram pela Habilitação em Ciências da Natureza, quanto os que optaram por Ciências Humanas e Sociais. A divisão das turmas só ocorre a partir do $3^{\circ}$ período, sendo, portanto, a disciplina em questão, comum para as duas habilitações.

Os alunos são oriundos, em sua maioria, de comunidades rurais, assentamentos, comunidades quilombolas e ribeirinhas. A maioria tem sua fonte de renda no campo, sendo que apenas um aluno mora e trabalha na zona urbana. Aproximadamente $30 \%$ dos estudantes atuam como docentes em escolas do campo. A maioria dos alunos está a muitos anos sem estudar, sendo esse um dos motivos das muitas dúvidas evidenciadas em relação aos conteúdos de matemática ministrados. Muitos deles, inclusive, alegaram "não gostar" de matemática, por esse motivo optaram pela habilitação em Ciências 
Humanas e Sociais, mas, sendo a disciplina de matemática comum às duas áreas, deviam obrigatoriamente matricular-se.

Desses alunos que trabalham no campo, pôde-se perceber diversidade de culturas, ocupações, origens, costumes. A maioria mora e trabalha no campo, em pequenas propriedades, muitos em assentamentos da reforma agrária, outros em comunidades quilombolas ou ribeirinhas. Seu sustento vem de culturas de café, cacau, pimenta, jiló, pitaia, alface, criação de peixes, na produção de leite e derivados, também na criação de frangos e um aluno trabalha com fabricação de blocos de concreto.

Em conversa com os estudantes, nas primeiras aulas, observou-se que muitos não organizavam suas finanças, ou seja, não tinham noção de quanto obtinham de lucro ou prejuízo em sua pequena propriedade. Muitos relatavam dificuldade no registro e cálculos de produção, e não possuíam o hábito de organizar uma planilha de entrada e saída de capital. Inclusive, alguns alunos se reportaram a camponeses que desistiram do trabalho no campo, por não conseguir organizar-se financeiramente.

Devido às diversidades presentes na turma, o desenvolvimento da atividade levou em consideração o trabalho exercido em sua comunidade. Pelo alto índice de relatos acerca das dificuldades em organizar suas finanças, realizamos um trabalho com base na etnomatemática, retomando e registrando os gastos na produção das culturas, serviços e produtos envolvidos no trabalho campesino.

\section{2- O Caminho percorrido}

Nossa intenção foi de analisar uma atividade didática desenvolvida na disciplina de Introdução à Matemática, fundamentada na etnomatemática. $O$ trabalho proposto baseou-se na ideia de que a etnomatemática não é um método em si, mas um processo pedagógico que não se ensina, vive-se e se faz mergulhando no universo sociocultural, compartilhando das várias concepções de mundo que estão inseridas entre aquelas paredes escolares. Existem muitas atividades em cada cultura que possuem componentes matemáticos que podem 
ser identificados, estudados e relacionados à matemática corrente. A proposta partiu da seguinte questão: Os agricultores fazem matemática?

Após a questão inicial, solicitou-se o seguinte trabalho aos estudantes:

-No primeiro momento, escolha de um produto/serviço, pesquisa sobre dados, cálculo dos custos de produção e lucros. Foi proposto pensar em temas da realidade da comunidade, como por exemplo: a fabricação de pé de moleque, beiju, mel, leite, bolachas, pão, vinho, café, pimenta, a produção de queijo, a construção de casas, etc.

-No segundo momento, pesquisa com os conhecedores do assunto (agricultores, donas de casa, feirantes, etc.) de todos os componentes do custo (a matéria-prima, insumos, impostos e serviços) necessários para a produção, coleta de dados;

-Após, cálculos referentes às quantidades dos componentes do custo necessárias para produzir certa quantidade do produto. Observação e registro da linguagem matemática utilizada pela população pesquisada.

-Em seguida, pesquisa e cálculos do custo unitário (PU) de cada componente; cálculo do custo total do produto (CT); pesquisa ou determinação do preço de venda e cálculo da receita $(R)$; e, por último, cálculo do lucro $(L)$ da atividade econômica.

-Registro dos cálculos em linguagem matemática. Observar as diferentes linguagens existentes para expressar a linguagem matemática. Fazer uso de cálculos, estimativas, símbolos, variáveis, tabelas, gráficos, fórmulas, modelos.

-Por último, sistematização dos resultados em uma planilha e organização uma apresentação oral para a turma.

A partir dessa proposta, foi realizada, neste estudo, a análise qualitativa e interpretativa (DENZIN; LINCOLN, 2006) de todo o percurso do trabalho, bem como das apresentações orais e escritas efetivadas pelos estudantes.

\section{Análise e discussão dos resultados}

Inicialmente, pensamos em organizar a proposta junto à turma, democraticamente, porém, como a turma era grande e nossa experiência ainda 
restrita, comunicamos à classe de alunos a ideia do trabalho. Porém, não se sabia ao certo qual seria a receptividade dos mesmos em relação à proposta. Após apresentar à turma, foi unânime o interesse dos discentes, principalmente aqueles que possuíam um pensamento preconcebido da matemática como algo exaustivo, de difícil compreensão e sem relação com o cotidiano. Os estudantes que apresentavam uma imagem negativa da matemática, foram os que se mostraram mais entusiasmados com a proposição do trabalho. De acordo com Fragoso (2001, apud Mendes e Carmo, 2014), as dificuldades em matemática podem estar relacionadas a fatores emocionais oriundos de processos pedagógicos mal direcionados em sala de aula. Tais situações podem gerar pensamentos negativos, aversão, medo e concepções inadequadas em relação à disciplina.

Após retornarem às suas comunidades de origem, no Tempo Comunidade do curso, o próximo passo realizado pelos discentes para o desenvolvimento da atividade foi de buscar, dentro de suas comunidades ou propriedades rurais, uma cultura ou serviço, para iniciar as pesquisas, podendo ser de sua própria família ou vizinhos.

Durante o desenvolvimento do trabalho, em muitos casos, os estudantes visualizaram que há falta de organização no controle dos custos das atividades camponesas. A maioria percebeu que poderia agir de forma diferenciada, cuidando melhor do ambiente e saúde, com os mesmos gastos e ganhos. Alguns estudantes descobriram que não estavam tendo lucro com a atividade. Outros ainda ficaram entusiasmados ao ouvir os relatos dos colegas, em relação ao tempo necessário para que a atividade precisa para vir a dar lucros, ou a outras opções de matéria-prima utilizadas. Foi uma experiência que proporcionou a percepção de que a organização, a resistência e a educação matemática são aspectos fundamentais no trabalho de mulheres e homens camponeses.

Houve a explanação de trabalhos voltados para as culturas de: café, pimenta do reino, pitaya jiló, goiaba, aroeira, coco e atividades como: produção de beiju, alface, rapadura, leite, queijo, criação de galinhas, peixes e outros. Houve reflexão e discussão após cada pesquisa apresentada, com sugestões e questionamentos para aprimorar as atividades com menos gastos. Cada 
apresentação exibiu também, em sua parte introdutória, um pouco da realidade de cada comunidade, do produto/serviço investigado, da maneira como é realizada a produção, comercialização, época de plantio, cuidados, trazendo a realidade campesina para a aula de matemática.

Uma estudante (ALUNA 1), residente no Assentamento Pancada Grande-BA, pesquisou e expôs para turma o cacau, a cultura de subsistência de sua região.

\begin{abstract}
Naturalizado das regiões de floresta pluviais da América Tropical, o cacau é uma das frutas mais cultivados no extremo sul da Bahia, as cidades que se concentram nessa região recebem o nome de Costa do Cacau, devido à grande produção desta cultura. Na Bahia, 700 mil hectares de cacau distribuemse por 96 municípios. A permanência desta variedade no extremo sul baiano ocorre porque suas regiões de cultivo possuem solos profundos e ricos, com clima quente e úmido, e temperatura média de cerca de $25^{\circ} \mathrm{C}$. Por ser mais resistente a doenças como a vassoura de bruxa, principal praga que afeta as plantações de cacau, essa variedade é geralmente utilizada para chocolates comerciais por possuir um sabor forte e específico (ALUNA 1).
\end{abstract}

As planilhas realizadas pelos estudantes utilizaram linguagem diferenciada, pois foi observada a linguagem matemática utilizada pelas populações. A Tabela 1 expõe os custos de produção da lavoura de cacau.

A tabela foi construída juntamente com uma agricultora, detalhando os estágios para o cálculo de seu capital investido e renda líquida. Na primeira coluna da tabela está descrito os serviços e produtos utilizados no manejo como limpeza, aplicação de calcário, adubo e poda. Na segunda, os dados coletados do período de aplicação, que foi do mês de maio/2017 a junho/2018. Na terceira coluna, a quantidade, logo em seguida o valor unitário dos produtos e por fim o valor total. Após calcular e analisar os dados pôde-se concluir que a entrevistada aplicou $\mathrm{R} \$ 1.180,00$ em sua cultura; teve $\mathrm{R} \$ 3.000,00$ de produção, com 20 arrobas e $R \$ 1.820,00$ de renda líquida, conforme demonstrado na Tabela 1(ALUNA 1).

Custo de Produção da Lavoura de Cacau na safra 2016-2018

\begin{tabular}{lllll}
\hline Descrição & \multicolumn{1}{c}{ de $_{0}$} & 0 & 0 & 0 \\
Serviços e Produtos & $\begin{array}{l}\text { Maio/2017 } \\
\text { (06 dias) }\end{array}$ & 0 & 4 & 80 \\
\hline Limpeza & &
\end{tabular}




\begin{tabular}{lllll}
\hline $\begin{array}{l}\text { Aplicação } \\
\text { Calcário }\end{array}$ & $\begin{array}{c}\text { deOut/2016 } \\
(01 \text { dia })\end{array}$ & 0 & 13 & 260 \\
\hline Adubo & $\begin{array}{l}\text { Set/2016 } \\
(01 \text { dia })\end{array}$ & 0 & 120 & 840 \\
\hline Poda & $\begin{array}{l}\text { Set/2016 } \\
(15 \text { dias })\end{array}$ & 0 & 0 & 0 \\
\hline TOTAL DE CUSTOS1180 & & 150 & 3000 \\
\hline PRODUÇÃO & $\begin{array}{l}\text { Jun/2018 } \\
(03 \text { dias })\end{array}$ & 0 &
\end{tabular}

Tabela 1- Custo de Produção da Lavoura de Cacau na safra 2016-2018 Fonte: Aluna 1.

Já a Tabela 2 apresenta os custos da produção de leite (Aluno 2), de um produtor do município de Alcobaça-BA.

\begin{tabular}{lllll}
\hline Relação & Período & Quantidade & Valor U.N & Valor Final \\
\hline Funcionário & & 1 & 600 & 1200 \\
\hline Pasto Alugado & 0 & 20 & 0 & 800 \\
\hline Sal Branco & 0 & 0 & 10 & 60 \\
\hline Fosboi & 0 & 4 & 140 & 560 \\
\hline Remédios & 0 & 1 & 300 & 300 \\
\hline Carrapaticida & 0 & 1 & 60 & 60 \\
\hline Puor on & 0 & 120 & 120 \\
\hline $\begin{array}{l}\text { Total } \\
\text { despesas }\end{array}$ & de & & & 3100 \\
\hline $\begin{array}{l}\text { Quantidade } \\
\text { Leite }\end{array}$ & de0 & 0 & 0 & 4200 \\
\hline $\begin{array}{l}\text { Renda Liquida } \\
\text { Tabela 2-Custo de Produça de }\end{array}$ & & & 800 \\
\hline
\end{tabular}

Tabela 2- Custo de Produção de leite. Fonte: Aluno 2.

Segundo relato do Aluno 3, muito se vem tentando, na região norte do Espírito Santo, inserir novas fontes de renda e meios de cultivar o solo. A partir dos movimentos sociais, os municípios vêm mudando a produção de alimentos, "além de produzir diversidade, vem construindo conceitos agroecológicos e orgânicos com uma hegemonia popular". O Aluno 3 também cita como exemplo,

O Movimento dos Pequenos Agricultores-MPA, já conseguiu grandes avanços no município, muitas famílias, desde 2007 já vem produzindo alimentos saudáveis, com diversidade, 
qualidade e quantidade dando conta de atender demandas como pnai, paa, população em geral e feiras livres no próprio município em localidades aos redores (ALUNO 3).

Sendo assim, trabalhando dentro da lógica da agroecologia e diversidade, o Aluno 3 apresentou um estudo sobre a produção de alface em sua propriedade, que está exposto nas Tabelas 3 e 4 a seguir:

\begin{tabular}{lll}
\hline Atividade & Valor Bruto & Por Muda (Real) \\
\hline Sementes & 0 & 0,01 \\
\hline Substrato & 0 & 0,02 \\
\hline Energia & 15 reais $\div 20$ bandejas: 0,75 & 0,01 \\
& 0,75 reais $\div 128$ cédulas por bandeja & \\
\hline Mão de Obra & 480 minutos $=60$ reais & 0 \\
& 40 minutos $=x$ reais $=5$ reais & \\
& 5 reais $/ 20$ bandejas $=0,25$ reais & \\
\hline Total por Muda & 0,25 reais / 128 cédulas $=$ &
\end{tabular}

Tabela 3- Custo da Produção de 1 Muda de Alface

Fonte: Aluno 3

\begin{tabular}{lll}
\hline Atividade & Valor Bruto & Por Pé (Real) \\
\hline Esterco & 200 reais $\div 16000 \mathrm{~kg}: 0,0125$ & 0,01 \\
& 0,0125 reais $\times 4800 \mathrm{~kg}$ usado no canteiro: 60 & \\
& 60 reais $\div 200$ mudas por canteiro: & \\
\hline Energia & 0 & 0,02 \\
\hline Mão de Obra & 5 diárias mensais & 0,09 \\
& $\begin{array}{l}\text { Valor da diária: } 60 \text { reais } \\
\\
\end{array}$ & \\
& $300 / 2400$ pés de alface $=$ & \\
\hline Total & 0 & \\
\hline
\end{tabular}

Tabela 4- Custo de Produção de 1 Pé de Alface

Fonte: Aluno 3

O Aluno 3 complementa sua pesquisa, com mais alguns cálculos,

Valor de produção do início da cadeia até o final: $3,7+11,85=$ 15.64 centavos

Percas consideradas durante a produção de $20 \%: 2400$ * $20 \%=$ 480 pés de alface perdidos.

Valor de comercialização pago para o mercado popular para comercializar $15 \%$ : 1920 * $15 \%=288$ pés de alface pagos pelo direito a comercialização.

Lucro $=2400-480-288-=1632$ pés de alface. 
Valor estimado em reais: 1632 * 1 real: 1632 reais

Valor liquido: 1632 - (0.1564 reais*1632): 1376,76 reais de lucro. Valor realista em uma amostra média de três meses: 1230 reais (ALUNO 3).

Tendo em vista estes dados, concordamos com os apontamentos de D`Ambrósio:

O cotidiano está impregnado dos saberes e fazeres próprios da cultura. A todo instante, os indivíduos estão comparando, classificando, quantificando, medindo, explicando, generalizando, inferindo e, de algum modo, avaliando, usando os instrumentos materiais e intelectuais que são próprios à sua cultura (D’ AMBRÓsIO, 2001, p. 22).

Outro ponto que as(os) estudantes perceberam e externalizaram em seus discursos foi que a matemática é vivenciada no cotidiano das comunidades, em todos os estágios, desde, por exemplo, a preparação do solo para plantação, a análise das distribuições das mudas, o tempo empregado em cada estágio do cultivo, e outros aspectos fundamentais à vida no campo. Os estudantes foram unânimes em afirmar que a matemática está mais presente na vida dos cidadãos do campo do que eles podiam imaginar, muitas vezes representada através de outras linguagens, que abrange aspectos sociais e culturais.

Entende-se que o ensino da matemática no contexto da educação do campo deva preparar o pensamento para enfrentar problemas e projetar soluções operativas, de acordo com Manechine e Caldeira (2009). Assim, é necessário que os alunos se debrucem sobre situações conflitantes, reais, e investigativas, procurando soluções, com o auxílio dos conhecimentos matemáticos. O marco das discussões que finalizaram a atividade foi a percepção da falta de organização financeira por parte dos estudantes e da importância da matemática na vida desses indivíduos: quilombolas, assentados, ribeirinhos, pequenos agricultores que lutam por seu direito à terra e por sua qualidade de vida, sendo a matemática grande aliada nessa luta.

Por fim, dois comentários dos alunos que merecem destaque: "Eu não sabia que minha propriedade tinha tanta matemática" (ALUNO 4), e o outro: "É, professora, mesmo nós, das humanas, não podemos fugir da matemática" (ALUNO 5). 


\section{Considerações finais}

A proposta de atividade no tempo comunidade da disciplina de introdução à matemática teve boa aceitação por parte das educandas e educandos, que procuraram conhecer mais sobre sua propriedade e seu trabalho no campo. Aliando pesquisa, valorização de sua identidade, cálculos, construção de planilhas e pesquisa, os estudantes se aproximaram da matemática de maneira agradável e com significado, no intuito de capacitar os trabalhadores camponeses a viver e produzir no campo com qualidade.

O trabalho respondeu às questões introdutórias, pois apresentou dados que mostram o papel da etnomatemática na educação do campo. A integração da educação matemática à resolução dos problemas cotidianos do campo, trazendo e matematizando situações reais, do contexto campesino, é também valorizar a cultura e diversidade da região e, ao mesmo tempo, questionar o conhecimento matemático hegemônico, no lugar de uma matemática seletiva e excludente.

\section{REFERÊNCIAS BIBLIOGRÁFICAS}

ANDRÉ, M. E. D. A. Estudo de caso em pesquisa e avaliação educacional. Brasília: Liberlivro, 2005.

BANDEIRA, Francisco de Assis. Pedagogia etnomatemática: reflexões e ações pedagógicas em matemática do ensino fundamental. Natal, RN: EDUFRN, 2016.

CALDART, Roseli Salete. Elementos para a construção do Projeto Político e Pedagógico da Educação do Campo. In: PARANÁ. Secretaria de Estado da Educação. Cadernos Temáticos: educação do campo. Curitiba: SEED-PR, 2005. p. 23-34.

CALDEIRA, AMA. org. Ensino de ciências e matemática, II: temas sobre a formação de conceitos [online]. São Paulo: Editora UNESP; São Paulo: Cultura Acadêmica, 2009. 287 p. ISBN 978-85- 7983-041-9. Available from SciELO Books <http://books.scielo.org>.

CEPLAC, Cacau história e evolução. Disponível em: <http://www.ceplac.gov.br/radar/radar_cacau.htm>. Acesso em: 05 de novembro,2018.

D'AMBROSIO, U. Etnomatemática: elo entre as tradições e a modernidade. Belo Horizonte: Autêntica, 2001. 
D’AMBROSIO, U. Prefácio. In BORBA, M. C.; ARAÚJO, J. L. Pesquisa Qualitativa em Educação Matemática. Belo Horizonte: Autêntica, 2004.

D'AMBROSIO, U. Ethnomathematics: link between traditions and modernity. Netherlands: Sense Publishers, 2006.

D'AMBROSIO, U. Etnomatemática, justiça social e sustentabilidade. Estud. av. vol.32 no.94 São Paulo Sept./Dec. 2018. Disponível em: https://doi.org/10.1590/s0103-40142018.3294.0014. Acesso em: 11/05/2020.

GOMIDE, Reynaldo. Operações unitárias: separações mecânicas. vol. 3. São Paulo: R. Gomide, 1980.

GRAMACHO, I. da C. P. et al. Cultivo e beneficiamento do cacau na Bahia. Ilhéus: CEPLAC, 1992.

KLINE, M. O fracasso da matemática moderna. São Paulo: IBRASA, 1976.

MARCHON, Fábio Lennon; FANTINATO, Maria Cecília. Possibilidades Filosóficas em Etnomatemática. Bolema, Rio Claro (SP), v. 29, n. 52, p. 549567, ago. 2015.

PINTO, Neuza B. Marcas históricas da Matemática Moderna no Brasil. Revista Diálogo Educacional/PUCPR. V.5, n. 16 (Set./dez. 2005). Curitiba: Champagnat, 2005, p.25-38.

SANGIORGI. O. 2007. L.H. Jacy Monteiro, grande matemático. Jornal O Estado de São Paulo. 06 jun. 1975. In: NAKASHIMA, Mario Nobuyuki. O papel da imprensa no movimento da matemática moderna. PUC/SP. 1 CD-ROM.

SOARES, Elenir Terezinha Paluch. Movimento da matemática moderna e o conceito de número natural. IX Congresso Nacional de Educação-EDUCERE. III Encontro Sul Brasileiro de Psicopedagogia, PUCPR, 26 a 29 de outubro, $2009 . \quad$ Disponível em: https://educere.bruc.com.br/arquivo/pdf2009/3076 1520.pdf. Acesso em nov. 2019.

STURTEVANT, W. C. Studies in ethnoscience. American Anthropologist, 66(3): 99-131,1964.

UFES. CEUNES. Projeto Pedagógico do curso de Licenciatura em Educação do Campo. CEUNES: São Mateus, 2012.

UFES. CEUNES. Projeto Pedagógico do curso de Licenciatura em Educação do Campo. CEUNES: São Mateus, 2019.

Sobre os Autores

Débora Schmitt Kavalek

quimicadebora@hotmail.com 
Doutora em Educação em Ciências pela Universidade Federal do Rio Grande do Sul (2016). É Professora do Magistério Superior (Adjunto A) sob o regime de dedicação exclusiva no Departamento de Educação e Ciências Humanas na Universidade Federal do Espírito Santo, campus São Mateus. Atua no Curso de Licenciatura em Educação do Campo CEUNES/UFES.

\section{Ariele Maria Santos dos Reis}

ariellymreis@gmail.com

Discente do curso de Licenciatura em Educação do Campo- Habilitação em Ciências Naturais- CEUNES/UFES. Bolsista PIBEX. 